\title{
A Three-Step Kinetic Mechanism for Peptide Binding to MHC Class II Proteins ${ }^{\dagger}$
}

\author{
Ravi V. Joshi, Jennifer A. Zarutskie, and Lawrence J. Stern* \\ Department of Chemistry, Massachusetts Institute of Technology, 77 Massachusetts Avenue, Cambridge, Massachusetts 02139 \\ Received October 11, 1999; Revised Manuscript Received January 13, 2000
}

\begin{abstract}
Peptide binding reactions of class II MHC proteins exhibit unusual kinetics, with extremely slow apparent rate constants for the overall association $\left(<100 \mathrm{M}^{-1} \mathrm{~s}^{-1}\right)$ and dissociation $\left(<10^{-5} \mathrm{~s}^{-1}\right)$ processes. Various linear and branched pathways have been proposed to account for these data. Using fluorescence resonance energy transfer between tryptophan residues in the MHC peptide binding site and aminocoumarin-labeled peptides, we measured real-time kinetics of peptide binding to empty class II MHC proteins. Our experiments identified an obligate intermediate in the binding reaction. The observed kinetics were consistent with a binding mechanism that involves an initial bimolecular binding step followed by a slow unimolecular conformational change. The same mechanism is observed for different peptide antigens. In addition, we noted a reversible inactivation of the empty MHC protein that competes with productive binding. The implications of this kinetic mechanism for intracellular antigen presentation pathways are discussed.
\end{abstract}

Proteins encoded by the major histocompatibility complex $(\mathrm{MHC})^{1}$ gene locus bind peptide antigens and display them at the cell surface for inspection by the immune system as part of the mechanism by which foreign material in the body is recognized and removed (1). Class II MHC proteins generally are found on specialized immune system cells such as B cells, macrophages, and dendritic cells, but they can be expressed by most cell types in response to inflammation or infection (2). Newly synthesized class II MHC $\alpha$ - and $\beta$-glycoprotein subunits associate with a chaperonin-like invariant chain protein, which places an extended loop in the class II peptide binding site and directs transport to an endosomal compartment (3). Endosomal proteins cleave the invariant chain, and the bound fragment is exchanged for peptides generated from cell-surface and endocytosed proteins, in a poorly characterized process catalyzed by the peptide-exchange factor HLA-DM (4). MHC-peptide complexes then are transported to the cell surface for inspection by $\mathrm{T}$-cell receptors on $\mathrm{CD}^{+} \mathrm{T}$ lymphocytes. Crystal structures have been determined for several human and murine class II MHC proteins in complex with defined peptides $(5-13)$. In each case, the peptide was bound in a polyproline type II-like conformation, with several side chains projecting into specificity-determining pockets within the overall peptide binding groove, and with many additional contacts between the MHC proteins and the main chain of the bound peptide.

\footnotetext{
† Supported by NIH Grants R01-AI38996 and PO1-GM56552, an HHMI Medical Student Research Fellowship (R.V.J.), and a Merck/ MIT Collaboration Predoctoral Fellowship (J.A.Z.).

* To whom correspondence should be addressed (e-mail: stern@ mit.edu, fax: 617-258-7847).

${ }^{1}$ Abbreviations: MHC, major histocompatibility complex; FRET, fluorescence resonance energy transfer; AMCA, 7-amino-4-methylcoumarin-3-acetate; PBST, phosphate-buffered saline containing $0.01 \%$ Tween-20 detergent.
}

Scheme 1

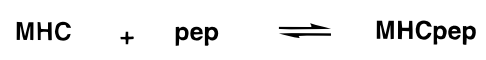

Initially, in vitro kinetic measurements of peptide binding to purified class II MHC proteins were interpreted in terms of the simple bimolecular reaction shown in Scheme 1 (14): Physical and chemical characterization of purified class II MHC revealed that they carried complex mixtures of tightly bound endogenous peptides (15-19). The stoichiometry of binding for peptide added to these preparations was quite low. Many of the natural peptide ligands had extremely long half-lives, often on the order of days, and could not be easily removed from the preparations without denaturing the $\mathrm{MHC}$ protein. Thus, for peptide binding in vitro to class II MHC proteins isolated from their native source, the predominant reaction is peptide exchange. Reactions of this type have been investigated in detail for several class II MHC proteins from humans and mice (20-22), but detailed kinetic analysis in this system is complicated by the exchange reaction and by heterogeneity in the mixture of endogenous peptides (23).

Production of empty, peptide-free class II MHC proteins simplified analysis of the binding reaction (24-28). Truncated class II MHC $\alpha \beta$ subunits comprising the soluble extracellular domain could be produced in recombinant insect cells, which assemble the $\alpha \beta$ heterodimer but do not load it with peptides (25). Recombinant HLA-DR1, a common human class II MHC protein, can be purified from such an expression system essentially free of endogenous peptides, and can be loaded to high efficiency with added peptides. For class II MHC proteins isolated from their native sources, the apparent forward rate constants determined in different laboratories varied from 1 to $100 \mathrm{M}^{-1} \mathrm{~s}^{-1}$, with the slow kinetics attributed to the requirement for dissociation of endogenous peptide $(14,29,30)$. The kinetics of peptide binding to the recombinant empty proteins were $\sim 10$-fold faster than for the native proteins, consistent with removal 
Scheme 2

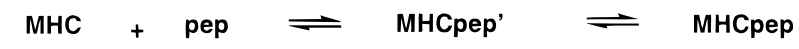

Scheme 3

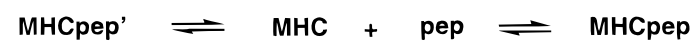

Scheme 4

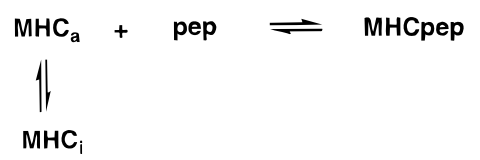

of the slow dissociation step from the overall reaction pathway $(25,31)$. Even for the empty protein, however, the apparent overall forward rate constant was still slow compared to the rates expected for a simple bimolecular reaction (25). This slow rate suggested a mechanism more elaborate than a simple bimolecular reaction $(31-36)$. The observation that peptide dissociation kinetics and electophoretic mobility of freshly formed complexes varied with incubation time suggested the presence of multiple peptide-bound species with different properties (31), consistent with either an onpathway intermediate as shown in Scheme 2 or a nonproductive off-pathway reaction as shown in Scheme 3. These two possible pathways lead to different physical mechanisms for the binding reactions. In the mechanism shown in Scheme 2 , an initial rapidly formed complex rearranges slowly to form a stable complex through conformational changes. In the mechanism shown in Scheme 3, most complexes form and dissociate rapidly, but occasionally a complex is formed in the stable conformation. This latter mechanism might occur, for example, if some fraction of peptides (or MHC proteins) in solution are not in the proper conformation for classical binding, but are able to form alternative complexes with varying stability (31). Finally, another pathway has been proposed recently, based on a careful analysis of peptide exchange reactions, in which the MHC protein is present in active and inactive states $(37,38)$, as in Scheme 4. A similar pathway with alternate peptide states is possible in principle but unlikely given the unfolded structure expected for short peptides in solution.

To differentiate among potential mechanisms such as those shown in Schemes 2, 3, and 4, we developed a spectroscopic method for determination of complex formation based on fluorescence resonance energy transfer (FRET) between tryptophan residues in the MHC peptide binding site and a fluorescent reporter group attached to the peptide. Previous methods for analysis of the binding reaction required separation of reactants and products for analysis, preventing characterization of the early steps in the reaction. Using the fluorescence assay, we observed the binding behavior for two different peptides. The binding reaction can be described completely by a pathway incorporating elements of Schemes 2 and 4. In addition, we derived the relevant kinetic parameters for the binding reactions. This pathway has several implications for the mechanism of peptide binding within a cell.

\section{EXPERIMENTAL PROCEDURES}

Peptides. Peptide variants of CLIP (Ac-VSRMRMATPL $\delta$ MQ, where $\delta$ is 2,4-diaminobutyric acid), derived from the class II-associated invariant chain (17), HA (Ac-PRFVKQNTLRLAT), derived from influenza virus hemagglutinin (14), and MA (Ac-SGPLKAEIAQRLE), derived from influenza virus matrix protein $(39-41)$, were synthesized by solid-phase FMOC chemistry, deprotected, purified by reverse-phase HLPC, and analyzed by matrix-assisted laser desorption mass spectrometry and quantitative amino acid analysis to confirm the absence of incomplete synthetic or deprotection products. Underscored side chains indicate positions of unique amino groups used for introduction of fluorescent labels. Native peptide sequences were modified by $\mathrm{K}$ to $\mathrm{R}$, and $\mathrm{K}$ to $\delta$ substitutions to facilitate single site labeling, at positions oriented away from the MHC protein, and were expected to have minimal effects on the MHCpeptide interaction based on structural modeling $(9,13)$. A Y-to-F change was made in the HA peptide to prevent intramolecular FRET. For fluorescent labeling, peptides were reacted overnight at room temperature in the dark with a 2-fold molar excess of 7-amino-4-methylcoumarin-3-acetic acid succinimide ester (AMCA-SE, Boehringer Mannheim) in $80 \%$ DMF or $100 \%$ DMSO, in the presence of 3 equiv of 2-diisopropylaminoethanol (Sigma). Modified peptides were again purified and analyzed as above. AMCA-peptide concentrations were measured by the absorbance at $346 \mathrm{~nm}$ $\left(\epsilon_{346 \mathrm{~nm}}=19000 \mathrm{M}^{-1} \mathrm{~cm}^{-1}\right)$.

HLA-DRI and Peptide Complexes. Soluble extracellular domains of HLA-DR1 were produced by baculovirusdirected secretion of recombinant protein from $S f 9$ insect cells with subsequent immunoaffinity purification, as described (25). Alternately, monomeric HLA-DR1 was produced by expression of $\alpha$ and $\beta$ subunits in $E$. coli inclusion bodies with folding in vitro (28), followed by immunoaffinity purification to isolate properly folded HLA-DR1 and subsequent size-exclusion chromatography (Phenomenex HPSEC 3000) to isolate monomer (42). HLA-DR1 produced in $S f 9$ cells carries three $\mathrm{N}$-linked high-mannose glycans, and C-terminal connecting peptide extensions to both subunits that are not present in HLA-DR1 produced in E. coli. Peptide-free ("empty") HLA-DR1 preparations were concentrated and exchanged into PBS $\left(7 \mathrm{mM} \mathrm{Na}{ }^{+} / \mathrm{K}^{+}\right.$phosphate, $135 \mathrm{mM} \mathrm{NaCl}, 0.02 \%$ sodium azide, $\mathrm{pH}$ 7.2) by centrifugal ultrafiltration (Amicon). The HLA-DR1 concentration was measured by the absorbance at $280 \mathrm{~nm}\left(\epsilon_{280 \mathrm{~nm}}=56340\right.$ $\mathrm{M}^{-1} \mathrm{~cm}^{-1}$ for Sf9 DR1 and $54375 \mathrm{M}^{-1} \mathrm{~cm}^{-1}$ for $E$. coli DR1).

For preparation of DR1-peptide complexes, purified empty protein $(10 \mu \mathrm{M})$ was incubated with a 2-3-fold molar excess of AMCA-peptide in PBST (PBS + 0.01\% Tween20) with protease inhibitors $(0.1 \mathrm{mM}$ iodoacetamide, $5 \mathrm{mM}$ EDTA, $0.1 \mathrm{mg} / \mathrm{mL}$ PMSF) at $37^{\circ} \mathrm{C}$ in the dark for $72 \mathrm{~h}$, with subsequent isolation of peptide complexes by sizeexclusion chromatography. Concentration and fractional peptide loading were determined by the absorbance at 280 nm using the appropriate $\epsilon_{280} \mathrm{~nm}$ values for DR1 and AMCA (5300 $\mathrm{M}^{-1} \mathrm{~cm}^{-1}$ ) and $\epsilon_{346} \mathrm{~nm}$ for AMCA. From the fluorescence emission intensities of free and bound peptides at equimolar concentrations, the AMCA-peptide extinction coefficient at $346 \mathrm{~nm}$ did not appear to change significantly after binding to DR1. Peptide binding capacities of DR1 preparations were measured by $12.5 \%$ SDS-PAGE after incubation as above, using the ability of DR1-peptide complexes to resist SDS-induced chain dissociation at room 
temperature to quantitate the amount of bound complex formed $(25,28)$. Purified DR1-peptide complexes were kept in the dark at $4{ }^{\circ} \mathrm{C}$.

To establish that the peptide labeling procedure did not substantially alter the binding affinity, apparent dissociation constants, $K_{\mathrm{D} \text {,app }}$, were measured by a competition assay with biotinylated HA peptide (bHA) and a sandwich ELISA using the LB3.1 antibody and streptavidin-europium as described previously $(42,43)$. For kinetically complex reactions such as those expected here, $K_{\mathrm{D} \text {,app }}$ determined by competition assay can vary depending on the assay conditions, and the relationship of $K_{\mathrm{D} \text {,app }}$ to the true equilibrium dissociation constant may not be straightforward (44). Peptides $\left(10^{-10}-\right.$ $\left.10^{-4} \mathrm{M}\right)$ were incubated with $0.5 \mathrm{nM} \mathrm{bHA}$ and $0.5 \mathrm{nM}$ empty Sf9 DR1 in PBST with $0.3 \%$ BSA and protease inhibitors at $37{ }^{\circ} \mathrm{C}$ for 3 days. An ELISA was used to detect the DR1bHA complex formed in this reaction, and the $\mathrm{IC}_{50}$ values were converted to an apparent $K_{\mathrm{D}}$ using the equation: $K_{\mathrm{D}, \text { app }}=\mathrm{IC}_{50} /\left[1+\left([\mathrm{bHA}] / K_{\mathrm{D}, \text { app,bHA }}\right)\right]$. The apparent $K_{\mathrm{D}}$ of bHA, $14 \mathrm{nM}$, was determined in a direct binding experiment by incubating $0.5 \mathrm{nM}$ empty DR1 and 2-fold dilutions of bHa $\left(10^{-11}-10^{-5} \mathrm{M}\right)$ under the conditions described above, using the ELISA to measure the DR1-bHA complex, and fitting the data to a quadratic equation describing a twocomponent binding reaction.

Fluorescence Spectra and Standard Curves. Fluorescence emission and excitation spectra were obtained using a SPEX Fluoromax-2 fluorescence spectrophotometer with slit widths of $1.0 \mathrm{~nm}$ (excitation) and $10.0 \mathrm{~nm}$ (emission). MHC-topeptide FRET was measured using $285 \mathrm{~nm}$ excitation and $447 \mathrm{~nm}$ emission, which correspond to peaks in the protein fluorescence excitation and AMCA emission spectra, respectively. To convert fluorescence intensities to MHCpeptide complex concentrations, standard conversion factors were obtained from fluorescence spectra of purified DR1, purified AMCA-labeled peptides, and purified MHC-peptide complexes at various concentrations $(5-500 \mathrm{nM})$ in PBST. The concentration dependence of fluorescence intensity was used to calculate the conversion factors $\gamma=7900 \mathrm{cps} / \mathrm{nM}$ DR1-Ha complex or $\gamma=7500 \mathrm{cps} / \mathrm{nM}$ DR1-CLIP complex and $\delta=1000 \mathrm{cps} / \mathrm{nM}$ for both free HA and CLIP peptide. For determination of the concentration of $\mathrm{MHC}-$ peptide complex $(C)$ in a mixture with total peptide $(P)$, the total fluorescence intensity $(F)$ was measured and converted to concentration by the formula: $C=(F-\delta P) /(\gamma-\delta)$.

Kinetic Measurements. For measurement of dissociation kinetics, purified $\mathrm{MHC}$ - peptide complexes (30 nM) were incubated with a 100-fold excess of unlabeled peptide in PBST at $37^{\circ} \mathrm{C}$ in the dark. At various times, samples were removed and immediately analyzed by size-exclusion chromatography in PBS (Phenomenex HPSEC3000), with the amount of complex determined using a Waters model 420-C fluorescence detector with $360 \mathrm{~nm}$ excitation and $425 \mathrm{~nm}$ long-pass emission filters. At the same time, another sample was removed, and fluorescence spectra were obtained as above for measurement of the complex by the FRET assay. Fluorescence values from size-exclusion chromatography were normalized by UV absorbance to control for variability of injection volume, and those from FRET spectra were normalized using the Raman spectra of a sample of deionized, distilled $\mathrm{H}_{2} \mathrm{O}\left(\lambda_{\mathrm{ex}}=350 \mathrm{~nm}\right)$ to correct for day-to-day differences in lamp intensity.
For measurement of association kinetics as initial rates of reaction, solutions of DR1 or peptide were prepared in PBST at twice the desired final concentration $(50 \mathrm{nM}-10 \mu \mathrm{M})$ and were warmed to $37^{\circ} \mathrm{C}$. To start the reaction, equal volumes of protein solution and peptide solution were mixed together in a $5 \mathrm{~mm}$ path length cuvette, and the increase in the FRET signal (447 $\mathrm{nm}$ emission intensity using $285 \mathrm{~nm}$ excitation) was measured at various times, typically at $1 \mathrm{~min}$ intervals for $30 \mathrm{~min}$. A constant concentration of DR1 (500 nM) was incubated with varying concentrations of peptide, or a constant concentration of peptide $(100 \mathrm{nM})$ was incubated with varying concentrations of DR1. Initial rates of association $\left(k_{\mathrm{obs}}\right)$ were determined from the slope of a linear fit to the early (linear) part of each association curve. For comparison of these slopes, association data are presented as changes in the concentration of complex relative to that at time zero as extrapolated from a linear fit to the initial data points. This treatment removes the contribution of any burst phase of complex formation. For protein titrations, the burst phase amplitude was determined by subtraction of the prereaction protein and peptide fluorescence from the extrapolated time zero value. Increase in fluorescence was converted into $\Delta \mathrm{nM}$ using the conversion factors described above, under the assumption of similar fluorescence intensities for the intermediate MHCpep' and final MHCpep complex. We note that MHCpep' and MHCpep need not have identical fluorescence intensities. For peptide titrations, the prereaction peptide fluorescence was large compared to the fluorescence changes in the initial phase of reaction, and the burst phase could not be determined accurately.

For determination of kinetic parameters $k_{2}$ and $K_{1}=k_{-1} /$ $k_{1}$, the initial rates of association $\left(k_{\mathrm{obs}}\right)$ were plotted against the concentration of either DR 1 or peptide. These plots were fit via nonlinear least squares to a quadratic equation describing the rate of formation of $\mathrm{MHC}-$ peptide complex in a linear two-step reaction (Scheme 2), where the first step is in rapid equilibrium and the second step does not backreact under initial rate conditions. This equation is

rate $=k_{2}\left\{\left[\left(\mathrm{MHC}_{\mathrm{T}}+\operatorname{pep}_{\mathrm{T}}+K_{1}\right) \pm\right.\right.$
$\left.\left.\sqrt{\mathrm{MHC}_{\mathrm{T}}{ }^{2}+\mathrm{pep}_{\mathrm{T}}{ }^{2}+K_{1}{ }^{2}+2 \operatorname{pep}_{\mathrm{T}} K_{1}+2 \mathrm{MHC}_{\mathrm{T}} K_{1}-2 \mathrm{MHC}_{\mathrm{T}} \mathrm{pep}_{\mathrm{T}}}\right] / 2\right\}$

where $\mathrm{MHC}_{\mathrm{T}}$ and pep $_{\mathrm{T}}$ are the total concentrations at time zero, $K_{1}$ is the apparent equilibrium constant for the first step, and $k_{2}$ is the forward rate constant for the second step. The apparent active MHC fraction was determined by comparison of the best-fit $\mathrm{MHC}_{\mathrm{T}}$ with the actual $\mathrm{MHC}$ concentration used in the experiment.

For measurements of the overall reaction progress, fluorescence changes were measured over several days for a reaction mixture containing $100 \mathrm{nM}$ DR1 and $100 \mathrm{nM}$ peptide at $37{ }^{\circ} \mathrm{C}$. Fluorescence values from the progress curves were converted to concentration of $\mathrm{MHC}-$ peptide complex as described above and fit to single or double exponentials.

For measurement of the temperature dependence of the reaction, initial rate experiments were performed with 500 $\mathrm{nM} S f 9 \mathrm{DR} 1$ and 50 or $300 \mathrm{nM}$ HA peptide at 25, 30, 35, 40 , and $45{ }^{\circ} \mathrm{C}$. Initial rate versus temperature data were analyzed by a modified Arrhenius plot: $\ln r=-E_{\mathrm{A}} / R T+$ $\ln A$, where $r$ is the reaction rate (rather than the rate 
constant), $E_{\mathrm{A}}$ is the activation energy of the reaction, and $A$ is the frequency factor, using a least-squares fit.

For stopped-flow measurements, fluorescence data from a reaction between $1 \mu \mathrm{M}$ DR 1 and $100 \mathrm{nM}$ HA peptide at $37{ }^{\circ} \mathrm{C}$ were collected on a logarithmic time base using a Hi-Tech SF-61 DX2 double mixing stopped-flow system with $285 \mathrm{~nm}$ excitation and detection at $425 \mathrm{~nm}$. The dead time of this instrument is $\sim 2 \mathrm{~ms}$. The data were fitted to a single exponential using a nonlinear least-squares fit.

\section{RESULTS}

Fluorescence Energy Transfer Assay. To measure the kinetics of peptide binding to the human class II MHC protein HLA-DR1, we developed a fluorescence energy transfer method that allows assay of the binding reaction in situ and in real time. Previous studies of peptide binding to MHC proteins have been complicated by protocols that disturb the binding reaction to separate bound from free peptide for analysis, such as gel filtration or electrophoresis $(31-38)$. The separation times for these methods can be long compared to the processes of interest, particularly for shortlived complexes or intermediate states. To measure peptide binding in real time, we used fluorescence energy transfer between MHC tryptophan residues and a fluorescent reporter group attached to the peptides. There are 10 tryptophan residues in DR1, with 4 in the peptide binding site and 6 in the lower immunoglobulin domains $(5,13)$. Of the residues in the binding site, two conserved tryptophans directly contact the bound peptide and two are within $15 \AA$ from a peptide side chain. These are all well within the characteristic Förster transfer distance of $\sim 30 \AA$ expected for tryptophan and commonly used fluorescent probes $(45,46)$. After testing several probes for high quantum efficiency of transfer, maximum overlap between tryptophan emission and probe excitation, and minimum overlap between tryptophan excitation and probe excitation, we chose 7-amino-4-methylcoumarin-3-acetate (AMCA) as a fluorescent probe. The fluorophore was attached to the peptide ligands through a 2-acetamido ester linkage to a peptide lysine or diaminobutyric acid residue.

We used peptides based on the well-characterized DR1 ligands CLIP (Figure 1a) [from the class II-associated chaperonin invariant chain (17)] and HA (Figure 1b) and MAT (Figure 1c) [derived from influenza virus hemagglutinin and matrix proteins, respectively (39-41)]. Crystal structures are available for HA complexed with DR1 (13), and for CLIP complexed with the closely related allele HLADR3 (9). For the complex with MAT peptide, no structure is available, but the peptide register and orientation appear to be the same as observed in the DR1-HA and DR3-CLIP complexes, based on studies of the effects of peptide substitution on the binding affinity $(47-49)$. To minimize any interaction of the AMCA probe with the DR1-peptide binding reaction, we attached the probe to side chains at positions oriented away from the binding site, at position P2 (MAT), P3 (HA), and P8 (CLIP), numbered relative to the large hydrophobic side chain at $\mathrm{P} 1$ that binds into MHC binding site pocket 1 (13). Introduction of the AMCA label did not affect the apparent affinity of peptide binding (Table 1). Additionally, Lys-to-Arg changes were introduced in MAT and HA to simplify labeling, and Tyr-to-Phe in HA

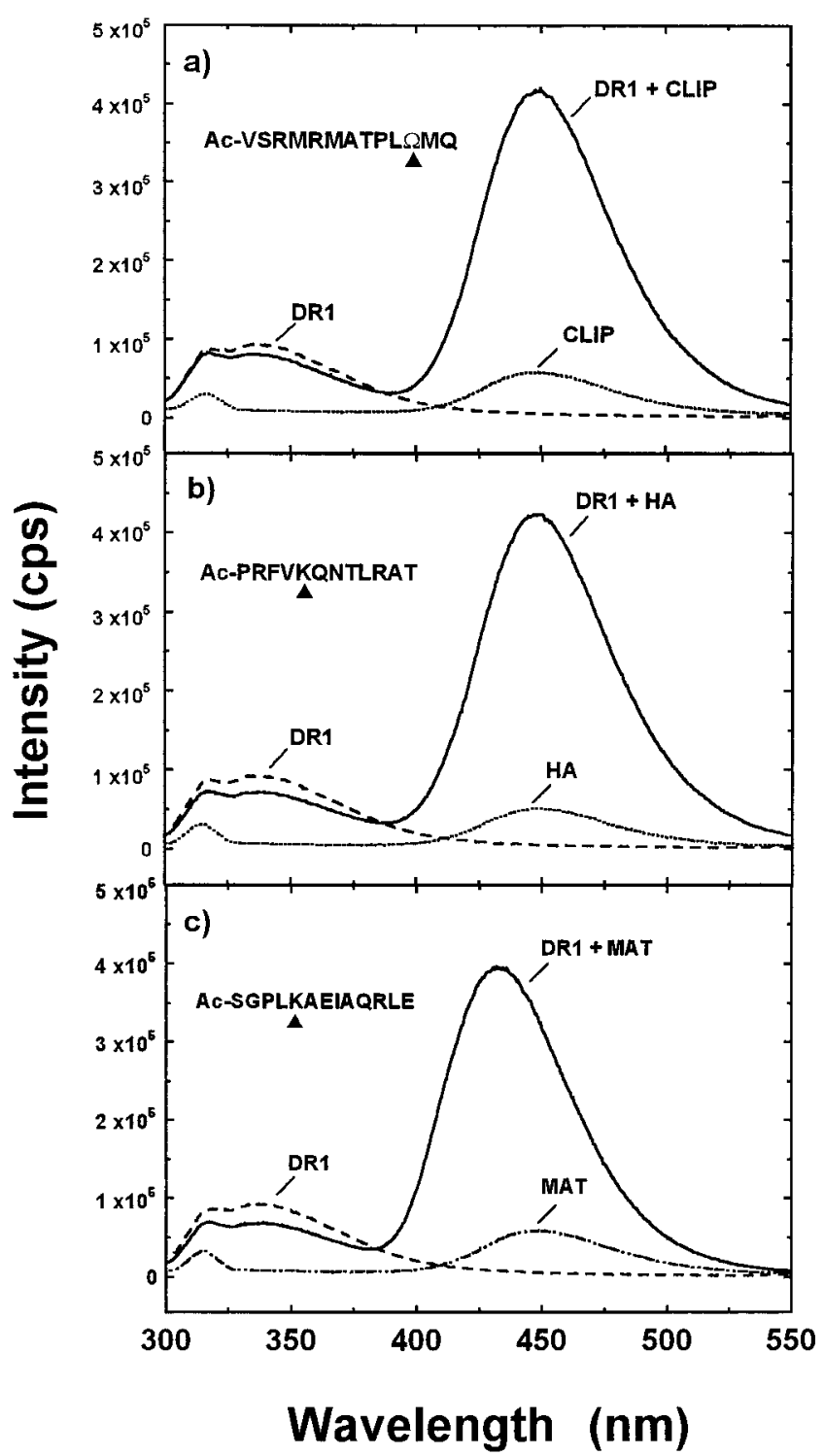

FIGURE 1: Fluorescence energy transfer assay of peptide binding to DR1. Fluorescence emission spectra of uncomplexed DR1 (dashed line), free AMCA-labeled peptide (dotted line), and DR1peptide complex (solid line), obtained at $50 \mathrm{nM}$ using $285 \mathrm{~nm}$ excitation, are shown for AMCA-labeled invariant chain peptide (CLIP, panel a), influenza hemagglutinin peptide (HA, panel b), and influenza matrix peptide (MAT, panel c), with peptide sequences shown in the upper left of each panel and position of AMCA label indicated by the arrowhead below the sequence. Each peptide shows a substantial increase in emission intensity upon binding to DR1, due to resonance energy transfer from aromatic residues in the binding site.

to reduce intrapeptide energy transfer. These changes are not expected to substantially alter the peptide binding affinity $(49,50)$. For production of $\mathrm{MHC}-$ peptide complexes, soluble peptide-free DR1 was produced in baculovirusinfected insect cells as described (25), and loaded with AMCA-labeled peptides (see Experimental Procedures). In complex with DR1, each of the peptides exhibited increased fluorescence intensity at $400-500 \mathrm{~nm}$ with excitation at 285 $\mathrm{nm}$, indicative of strong fluorescence resonance energy transfer (FRET) between aromatic amino acid residues in the MHC protein and the peptide AMCA (Figure 1). AMCAMAT exhibited on binding to DR1 small shifts in both excitation and emission maxima and in probe quantum yield (Figure 1c, Table 1), indicating a physical interaction between 


\begin{tabular}{|c|c|c|c|c|c|}
\hline peptide & $\begin{array}{c}\text { excitation } \lambda_{\max }{ }^{a} \\
(\mathrm{~nm})\end{array}$ & $\begin{array}{c}\text { emission } \lambda_{\max }{ }^{b} \\
(\mathrm{~nm})\end{array}$ & $F_{\text {bound }} / F_{\text {free }}{ }^{c}$ & $\begin{array}{c}K_{\text {d,app }}(\text { unlabeled }) \\
(\mathrm{nm})\end{array}$ & $\begin{array}{c}K_{\text {d,app }}(\text { MCA-labeled }) \\
(\mathrm{nm})\end{array}$ \\
\hline HA & $285,350(350)$ & $447(445)$ & 7.9 & 1.1 & 1.4 \\
\hline CLIP & $285,350(350)$ & $447(445)$ & 7.7 & 1.3 & 3.6 \\
\hline MAT & $285,360(350)$ & $432(445)$ & 8.9 & $\mathrm{n} / \mathrm{d}^{d}$ & $\mathrm{n} / \mathrm{d}$ \\
\hline
\end{tabular}

${ }^{a}$ Fluorescence excitation maxima for $445 \mathrm{~nm}$ emission. The shorter wavelength represents energy transfer from DR1, and the longer wavelength direct excitation of the AMCA fluorophore. Values in parentheses are for the uncomplexed peptide. ${ }^{b}$ Fluorescence emission maxima using $285 \mathrm{~nm}$ excitation. Values in parentheses are for uncomplexed peptide. ${ }^{c}$ Ratio of fluorescence intensities for bound versus free peptide, using $285 \mathrm{~nm}$ excitation and 445 (HA, CLIP) or $432 \mathrm{~nm}$ (MAT) emission. ${ }^{d}$ Not determined.
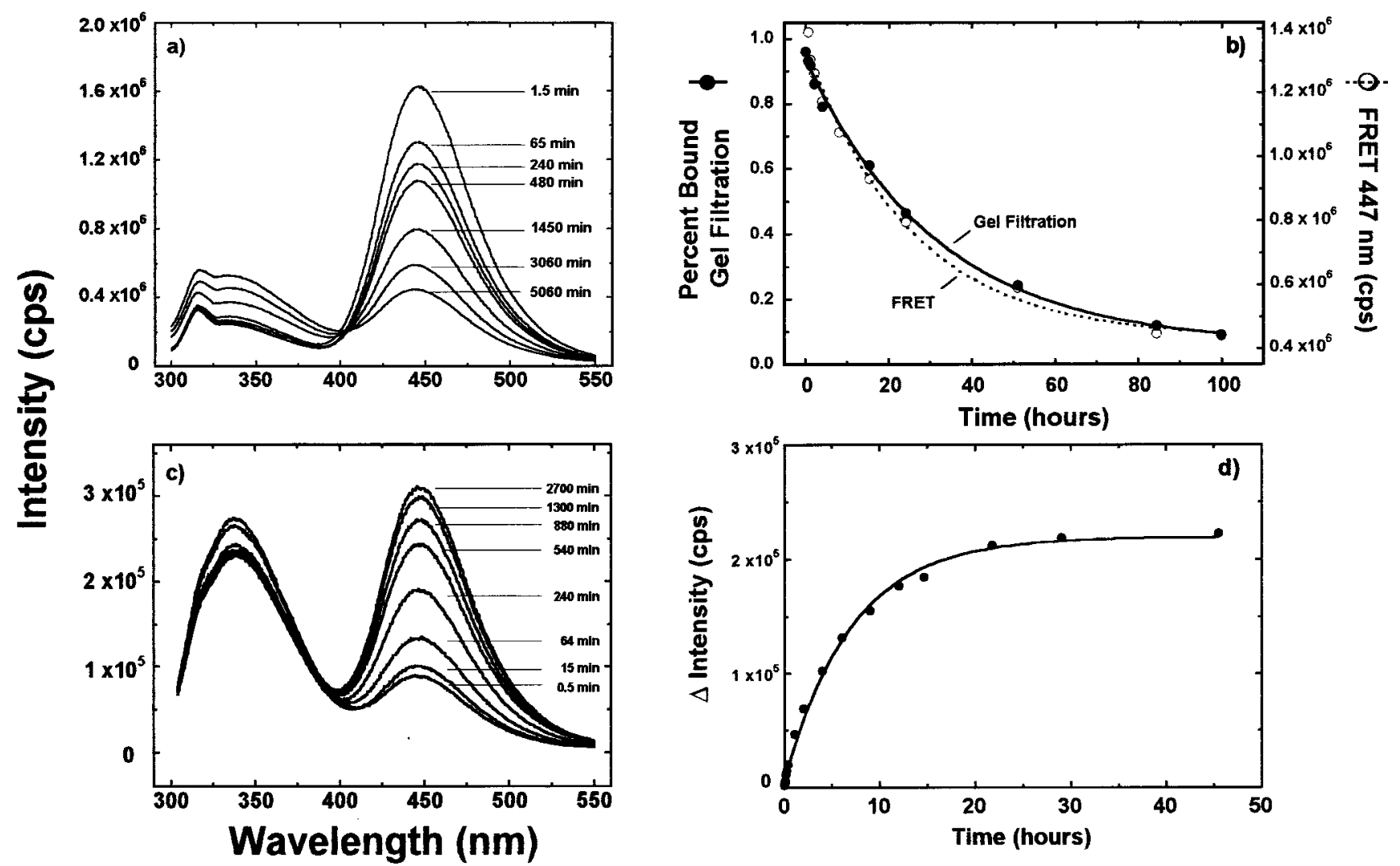

FIGURE 2: Peptide binding kinetics. (a) Dissociation assay for DR1-CLIP complex, with emission spectra recorded at $37{ }^{\circ} \mathrm{C}$, pH 7.2 , at indicated times after addition of excess unlabeled peptide $(2.7 \mu \mathrm{M})$ to purified complex (32 $\mathrm{nM}$, formed by incubation of DR1 with labeled peptide for $72 \mathrm{~h}$ at $37{ }^{\circ} \mathrm{C}$ with subsequent purification). Emission intensity decreases with time, indicating dissociation of labeled peptide. (b) Peak intensities for energy transfer (FRET $447 \mathrm{~nm}$ ) from panel a (open symbols) plotted against dissociation time, shown along with data from conventional gel filtration assay (filled symbols) of the same dissociation reaction. The solid line represents a single-exponential fit to the FRET data $(\tau=28 \mathrm{~h})$; dashed line, gel filtration data $(\tau=31 \mathrm{~h})$. (c) Association assay for DR1-CLIP complex, with emission spectra recorded at indicated times after addition of AMCA-labeled peptide $(100 \mathrm{nM})$ to empty DR1 $(100 \mathrm{nM})$ at $37^{\circ} \mathrm{C}$, pH 7.2 . Emission intensity at $447 \mathrm{~nm}$ increases with time, indicating binding of labeled peptide. (d) Change in fluorescence intensity at $447 \mathrm{~nm}$ plotted against association time. The solid line represents a single-exponential fit as described under Experimental Procedures. A slower binding phase $(\tau \sim 50 \mathrm{~h})$ is not apparent on this scale.

the AMCA probe and the MHC site. Because this interaction might alter the peptide-MHC binding reaction, this peptide was not investigated further. AMCA-HA and AMCA-CLIP were used to probe peptide binding kinetics.

To test the utility of the substantial difference in the fluorescence energy transfer for the bound versus free peptide in an assay of MHC peptide-binding kinetics, we measured dissociation kinetics for the DR1-CLIP complex (Figure 2a). The $447 \mathrm{~nm}$ emission band, representing energy transfer from DR1 to the bound peptide, decreases with increasing time as the peptide dissociates. The $330 \mathrm{~nm}$ emission band, representing emission from aromatic groups in uncomplexed DR1, increases concomitantly. The kinetics of these changes correlate with peptide release as measured in a conventional gel filtration assay performed on the same samples in parallel
(Figure $2 \mathrm{~b}$ ). For CLIP, dissociation at $37^{\circ} \mathrm{C}$ proceeds with $k_{\text {off }}=1.0 \times 10^{-5} \mathrm{~s}^{-1}(\tau=28 \mathrm{~h})$, in agreement with previous work (51). We were able to use the same system to measure association kinetics. An association reaction (Figure 2c) exhibited single-exponential binding kinetics (Figure 2d), with $k_{\mathrm{obs}}=5.8 \times 10^{-4} \mathrm{~s}^{-1}(\tau=28.7 \mathrm{~min})$, corresponding to an apparent forward rate constant of $\sim 100 \mathrm{M}^{-1} \mathrm{~s}^{-1}$. This value is in accord with some but not all published values for this or similar reactions $(14,25,29-31)$. Thus, the changes in fluorescence energy transfer reliably reflect peptide binding and dissociation.

Initial Rates of Reaction. We used the peptide association assay to investigate in detail the mechanism of peptide binding. Kinetic mechanisms such as shown in Schemes 1-4 can be distinguished based on the predicted reaction order 

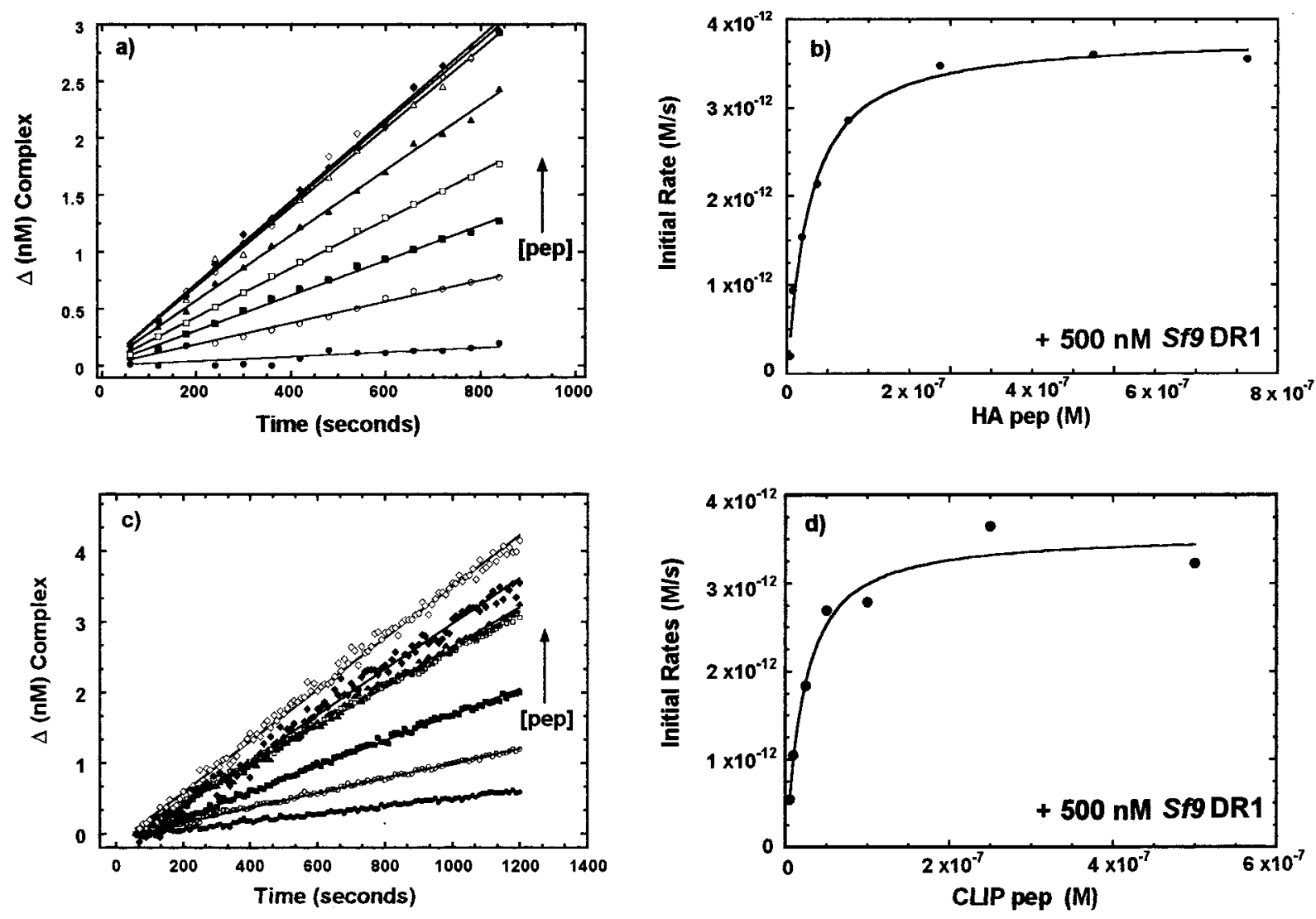

FIGURE 3: Initial rates with varying concentration of peptide. (a) Dependence of peptide binding kinetics on peptide concentration, using $500 \mathrm{nM}$ DR1 and varying concentrations $[(\bullet) 5 \mathrm{nM},(\bigcirc) 10 \mathrm{nM},(\boldsymbol{\square}) 25 \mathrm{nM},(\square) 50 \mathrm{nM},(\boldsymbol{\Delta}) 100 \mathrm{nM},(\Delta) 250 \mathrm{nM},(\diamond) 500 \mathrm{nM},(\diamond) 750$ $\mathrm{nM}$ ] of AMCA-HA peptide. Changes in concentration relative to an extrapolated time zero value are shown (see Experimental Procedures for details). (b) Initial rate of peptide binding plotted against HA peptide concentration. The rates were determined from linear fits to the

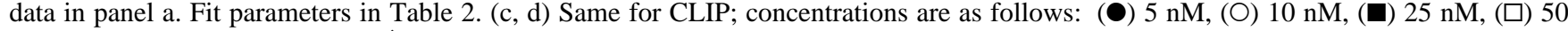
$\mathrm{nM},(\Delta) 100 \mathrm{nM},(\triangle) 250 \mathrm{nM},(\diamond) 500 \mathrm{nM}$.

for each of the reactants. For example, in a kinetic process described by Scheme 1, the rate of production of MHCpeptide complex will be first order with respect to both MHC and peptide concentrations. A process described by Scheme 2 will behave similarly at low reactant concentrations, when the first step is rate-limiting, but the rate will become independent of both $\mathrm{MHC}$ and peptide concentrations at high reactant concentrations, when the second, unimolecular step is rate-limiting. A process described by Scheme 3 will behave similarly to one described by Scheme 1, with production of MHC-peptide complex first order with respect to both reactants. If the rates of formation and decay of the off-pathway product MHCpep' are distinct from those of MHCpep, and if both MHCpep and MHCpep' species are detected, biphasic association curves will be observed, with both kinetic phases exhibiting first-order kinetics. A process described by Scheme 4 always will be first order in MHC concentration. The peptide order will depend on the extent to which the first reaction contributes to the observed kinetics. If the first reaction is rate-limiting, the reaction can become independent of peptide concentration; otherwise, the process again reduces to one described by Scheme 1 but with a reduced MHC concentration. To distinguish among these mechanisms, we measured the dependence of the initial rate of binding on the concentrations of MHC and peptide, for both HA and CLIP peptides.

Figure $3 \mathrm{a}, \mathrm{b}$ shows the dependence of the initial rate of binding on the concentration of HA, under conditions where the reaction has proceeded to less than 5\% completion. The rate increases with increasing peptide at moderate concentrations but saturates at high peptide concentration. Similar behavior was observed with the CLIP peptide (Figure 3c,d). The behavior at lower concentrations indicates the reaction is first order with respect to peptide concentration. At high concentrations, the behavior indicates a rate-determining step that does not involve peptide binding. This rate saturation is inconsistent with a simple one-step binding reaction (Scheme 1) or a reaction in which two forward first-order reactions compete (Scheme 3), but is consistent with more elaborate reactions such as Scheme 2 or Scheme 4. In a separate experiment, the concentration of peptide was fixed, and the concentration of DR1 varied (Figure $4 \mathrm{a}, \mathrm{c}$ ). The rate of binding saturated with increasing concentration of DR1 for both HA and CLIP peptides (Figure $4 \mathrm{~b}, \mathrm{~d}$ ). This indicates that the rate-limiting step at high concentration does not directly involve DR1. This behavior is consistent with Scheme 2, but inconsistent with Scheme 4. Thus, taken together, these results suggest a mechanism in which a bimolecular step involving both peptide and MHC predominates at low concentrations, and a second step directly involving neither peptide nor MHC predominates at high concentrations.

For a reaction described by Scheme 2, formation of the intermediate species MHCpep' in principle should be detectable by the FRET assay, as the energy transfer efficiency is likely to be substantial for any bound species. We attempted 

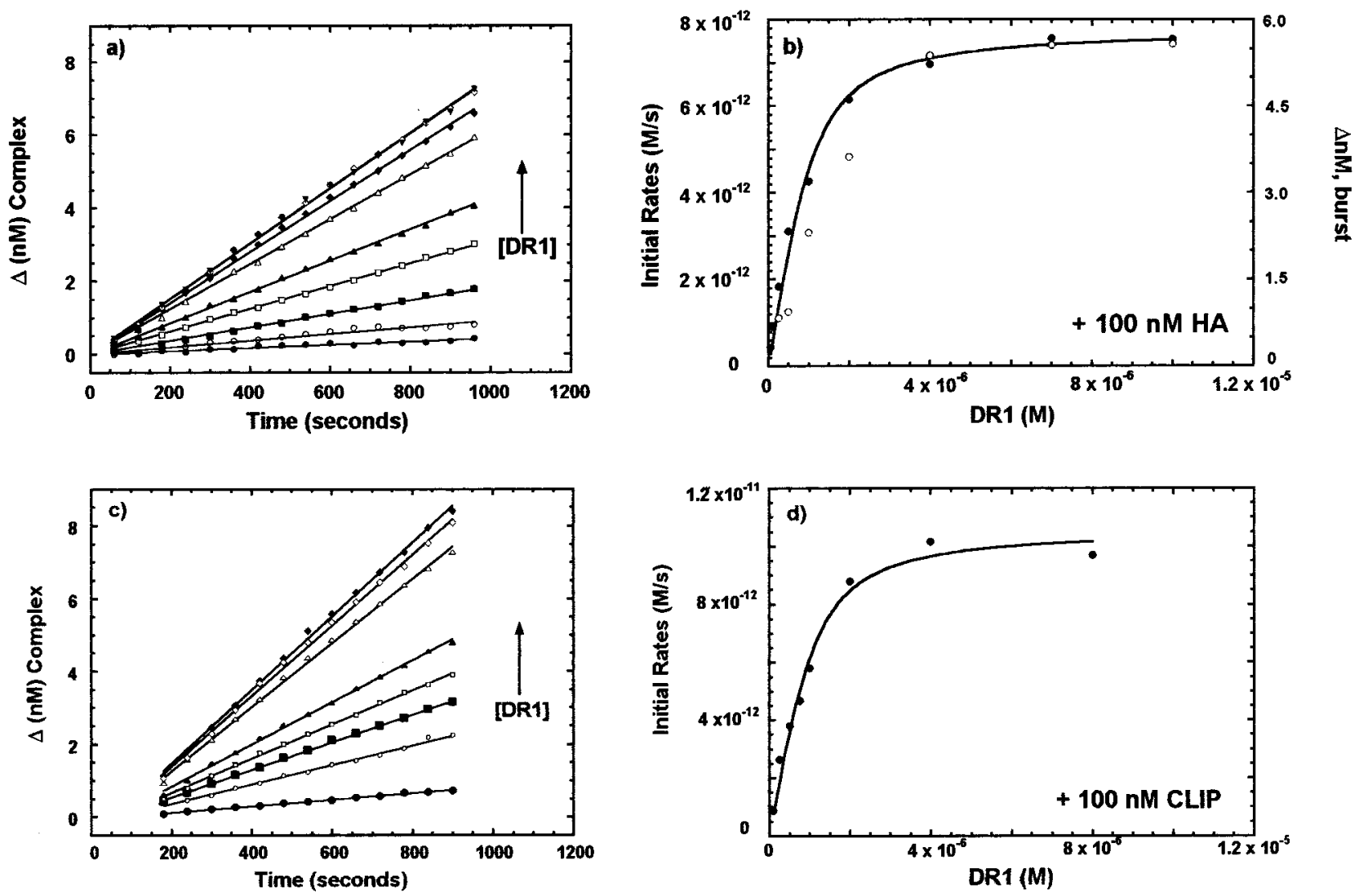

FIGURE 4: Initial rates with varying concentration of MHC. (a) Dependence of peptide binding kinetics on DR1 concentration, with 100 nM AMCA-HA and varying DR1 concentrations $[(\bullet) 50 \mathrm{nM},(\bigcirc) 100 \mathrm{nM},(\mathbf{\square}) 250 \mathrm{nM},(\square) 500 \mathrm{nM},(\Delta) 1 \mu \mathrm{M},(\Delta) 2 \mu \mathrm{M},(\diamond) 4 \mu \mathrm{M},(\diamond)$ $7 \mu \mathrm{M},(\nabla) 10 \mu \mathrm{M}$ ]. Changes in concentration relative to an extrapolated time zero value are shown (see Experimental Procedures for details). (b) Initial rate of peptide binding plotted against DR1 concentration. The amount of complex formed in the burst phase for each association reaction is shown as (O). (c, d) Same for CLIP; DR concentrations are () $100 \mathrm{nM},(\mathrm{O}) 250 \mathrm{nM},(\boldsymbol{\square}) 500 \mathrm{nM},(\square) 750 \mathrm{nM},(\mathbf{\Delta})$ $1 \mu \mathrm{M},(\triangle) 2 \mu \mathrm{M},(\diamond) 4 \mu \mathrm{M},(\diamond) 8 \mu \mathrm{M}$.
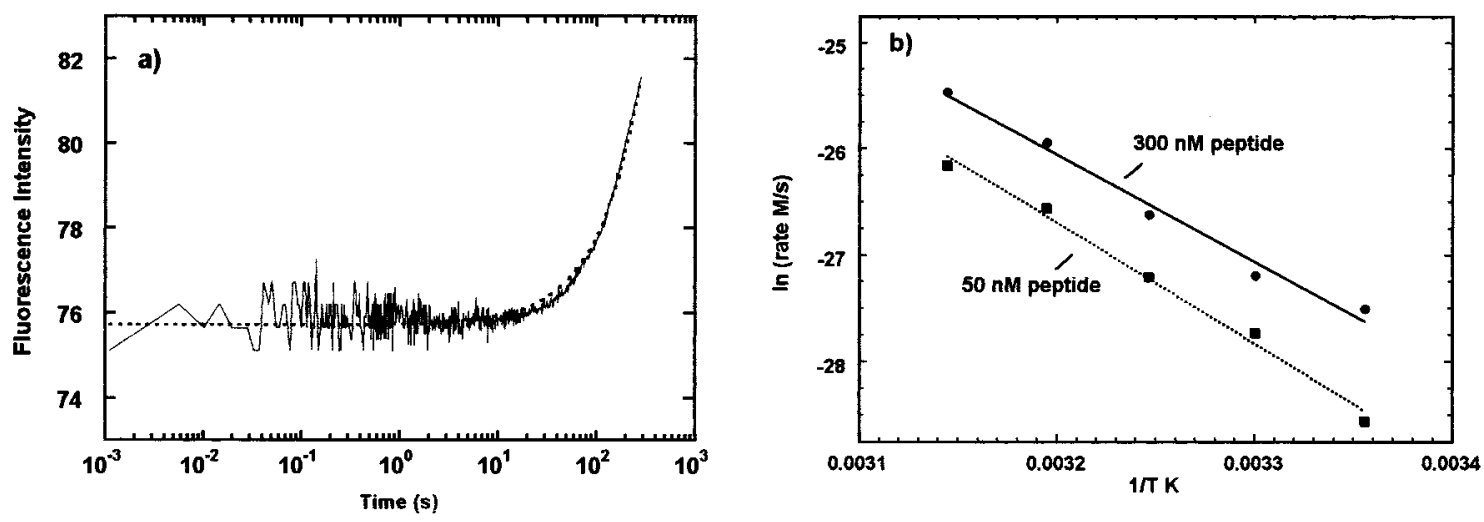

FIGURE 5: Early phase of the peptide binding reaction and temperature dependence of the rate constants. (a) Stopped-flow analysis of 100 nM AMCA-HA peptide and $1 \mu \mathrm{M}$ DR1, collected on a logarithmic time base with instrumental dead time $\sim 2 \mathrm{~ms}, 289 \mathrm{~nm}$ excitation, $>385$ $\mathrm{nm}$ emission. The dashed line is the single-exponential fit to the experimental data points (solid line) with $k_{\text {app }}=2.7 \times 10^{-4} \mathrm{~s}^{-1}$. (b) Arrhenius plots. See Experimental Procedures for details.

to investigate formation of a such a species as an early step in the peptide binding process that might be obscured by the mixing time $(\sim 30 \mathrm{~s})$ of the initial rate experiments shown in Figures 3 and 4. We used a stopped-flow apparatus to measure the fluorescence changes during the early phase of a binding experiment (Figure 5a). The increase in fluorescence signal with time $(10 \mathrm{~ms}-250 \mathrm{~s})$ for the reaction of $100 \mathrm{nM}$ AMCA-HA and $1 \mu \mathrm{M}$ DR 1 could be described by a single-exponential process with $k_{\text {app }}=2.7 \times 10^{-4} \mathrm{~s}^{-1}$, consistent with the initial rates of reaction observed in Figures 3 and 4 . Thus, any rapid kinetic step occurring early in the reaction was not resolved by the apparatus. However, we did find evidence for a rapid kinetic step in the comparison of the fluorescence intensities of each curve extrapolated to time zero in the initial rate experiment, with the intensities corrected for the calculated fluorescence of the unreacted protein and peptide components. This difference corresponds to a burst phase of complex formation (see Experimental Procedures). In Figure 4b, the amplitude of this burst phase is shown (open circles) along with the initial rate of complex formation (filled circles). For a reaction described by Scheme 2 with a rapid first step, both the initial rate of product 
Table 2: Kinetic Parameters ${ }^{a}$ for DR1-Peptide Complexes

\begin{tabular}{|c|c|c|c|c|c|c|c|c|c|c|c|}
\hline & & \multicolumn{4}{|c|}{ constant protein, variable peptide } & \multicolumn{6}{|c|}{ constant peptide, variable protein } \\
\hline & & $\begin{array}{l}k_{-1} / k_{1} \\
(\mathrm{nM})\end{array}$ & $\begin{array}{c}k_{2, \text { app }}{ }^{b} \\
\left(\times 10^{-4} \mathrm{~s}^{-1}\right)\end{array}$ & $\begin{array}{c}k_{2, \text { corr }}{ }^{b} \\
\left(\times 10^{-4} \mathrm{~s}^{-1}\right)\end{array}$ & $\%_{\text {act }}^{c}$ & $\begin{array}{c}k_{-1} / k_{1, \text { app }} b \\
(\mathrm{nM})\end{array}$ & $\begin{array}{c}k_{-1} / k_{1, \text { corr }}{ }^{b} \\
(\mathrm{nM})\end{array}$ & $\begin{array}{c}k_{2} \\
\left(\times 10^{-4} \mathrm{~s}^{-1}\right)\end{array}$ & $\%_{\text {act }^{c}}$ & $\begin{array}{c}k_{\text {act }} \\
\left(\times 10^{-6} \mathrm{~s}^{-1}\right)\end{array}$ & $\begin{array}{c}k_{\text {off }} \\
\left(\times 10^{-5} \mathrm{~s}^{-1}\right)\end{array}$ \\
\hline $\mathrm{DR} 1^{d}$ & HA & $32(4)$ & $0.08(0.02)$ & $3.8(0.1)$ & 2 & $800(50)$ & $29(7)$ & $0.8(0.02)$ & 10 & $6.3(0.7)$ & $0.09^{e}$ \\
\hline & CLIP & 17 (4) & $0.07(0.04)$ & $3.6(0.2)$ & 2 & $890(160)$ & $30(9)$ & $1.2(0.1)$ & 10 & $\mathrm{n} / \mathrm{a}^{f}$ & $1.0(0.1)$ \\
\hline $\mathrm{DR} 1_{\text {mon }^{g}}$ & $\mathrm{HA}$ & $13(1)$ & $0.17(0.01)$ & $8.4(0.1)$ & 2 & $4300(1200)$ & $8(4)$ & $8.5(0.3)$ & 3 & $4.3(0.4)$ & $\mathrm{n} / \mathrm{d}^{h}$ \\
\hline
\end{tabular}

${ }^{a}$ The values in parentheses reflect the uncertainty of the fit to the appropriate equations for the data as described under Experimental Procedures and Results. ${ }^{b}$ The subscript app indicates parameters calculated with the total MHC concentration taken to be $100 \%$ active. The subscript corr indicates parameters calculated with the MHC concentration scaled to reflect the active percentage of MHC given in the $\%_{\text {act }}$ column. ${ }^{c}$ Apparent active percentage of total DR1. Different preparations were used for the protein and peptide titrations for DR $1^{d}$; the same preparation for DR $1_{\text {mon }}{ }^{g}$. ${ }^{d}$ Produced in Sf9 insect cells. ${ }^{e}$ Reference $39 .{ }^{f}$ The progress curve for CLIP binding to DR1 does not have a substantial second phase, and thus the parameter for the rate of DR1 activation could not be estimated. ${ }^{g}$ Monomeric protein produced by refolding in vitro subunits expressed in E. coli. ${ }^{h}$ Not determined.

Scheme 5

$$
\begin{aligned}
\mathrm{K}_{1}=\mathrm{k}_{-1} / \mathrm{k}_{1} & \mathrm{k}_{2} \\
\mathrm{MHC}+\text { pep } & \rightleftharpoons \text { MHCpep' } \longrightarrow \text { MHCpep }
\end{aligned}
$$

formation and the burst phase amplitude will be proportional to the concentration of intermediate MHCpep' formed, essentially as observed.

We measured the initial rates of reaction at various temperatures, in an attempt to resolve the two kinetic processes observed above. However, Arrhenius plots (Figure $5 b)$ were similar under reaction conditions dominated by a unimolecular step (300 nM peptide) or reflecting both processes (50 nM peptide), with apparent activation enthalpies $\Delta H=20$ or $23 \mathrm{kcal} / \mathrm{mol}$, and entropies $\Delta S=-21$ and $-18 \mathrm{cal} \mathrm{mol}^{-1} \mathrm{~K}^{-1}$, respectively.

Kinetic Parameters. For the linear, two-step mechanism of Scheme 2, when the first step is rapid and the reaction is under initial rate conditions so that the back-reaction is minimal (Scheme 5), the kinetic behavior can be described by two parameters: a quasi-equilibrium constant $K_{1}=k_{-1} /$ $k_{1}$ and a bimolecular forward rate constant $k_{2}$. Under conditions where MHC is in large excess and its concentration is essentially constant during the reaction, the rate of complex formation can be described by a hyperbolic function (eq 2):

$$
\text { rate }=\frac{k_{2}[\mathrm{pep}][\mathrm{MHC}]}{k_{-1} / k_{1}+[\mathrm{MHC}]}
$$

At MHC concentrations that are low relative to $k_{-1} / k_{1}$, the equation predicts second-order reaction kinetics with rate $=$ $\left(k_{2} k_{1} / k_{-1}\right)[\mathrm{MHC}][\mathrm{pep}]$. As the MHC concentration increases, the $k_{-1} / k_{1}$ term ceases to contribute to the observed rate, which reaches a limiting value of $k_{2}$ [pep]. Without the assumption of one component in large excess, the rate is described by a quadratic equation that takes into account reactant depletion (eq 1, see Experimental Procedures), and which predicts a similar dependence of reaction order on reactant concentration. Using the quadratic equation, values were determined for the effective equilibrium constant $k_{1} /$ $k_{-1}$ and the saturating apparent rate constant $k_{2}$, for the peptide and protein titrations in Figures 3 and 4, for both HA and CLIP peptides (Table 2).

Surprisingly, the values for the kinetic parameters $k_{-1} / k_{1}$ and $k_{2}$ were different when derived from experiments with varying protein concentration than when they were derived from experiments with varying peptide concentration. The apparent constants $k_{-1} / k_{1, \text { app }}$ as determined in the constant peptide, variable protein titration were 25-fold (HA) and 52fold (CLIP) greater than those determined in the constant protein, variable peptide titration (Table 2). The apparent saturating rate constants $k_{2 \text {,app }}$ determined in the constant protein, variable peptide titration were $10-15$-fold smaller than the same parameters measured in the variable protein, constant peptide titration. An explanation for this behavior would be that only a fraction of total MHC protein participates in the kinetic processes contributing to the initial rate data. The effect of a proportion of inactive MHC would be to increase the concentration of MHC protein needed to reach the half-maximal initial rate, leading to an apparent $k_{-1} / k_{1}$ greater than the true value. However, the determination of $k_{2}$ would be unaffected, as the effect of the inactive fraction would be overcome at high concentrations of total MHC protein. For the peptide titration, any inactive MHC would have no effect on the peptide concentration needed to reach the half-maximal initial rate, and the true $k_{-1} / k_{1}$ would be observed. However, the observed saturating rate $k_{2}[\mathrm{MHC}]$ would lead to an erroneously low apparent value for $k_{2}$, as the rate would be divided by the (larger) total MHC concentration rather than the (smaller) active MHC value. To quantify these effects, we determined best-fit values for the active MHC fraction along with $k_{-1} / k_{1}$ and $k_{2}$ parameters in the analysis of the initial rate data. We determined that approximately $2-10 \%$ of the total DR 1 protein was able to participate in the initial rate processes, with the value varying somewhat between MHC preparations. Using these values for the active fraction, we were able to determine corrected values for $k_{-1} / k_{1, \text { corr }}$ from the protein titration, and $k_{2, \text { corr }}$ from the peptide titration. Under this model, the kinetic parameters derived from protein and peptide titrations were approximately equal, with $k_{-1} / k_{1} \sim 30 \mathrm{nM}$ and $k_{2} \sim 1 \times 10^{-4} \mathrm{~s}^{-1}$, for both HA and CLIP peptides (Table 2).

Overall Reaction Progress. We performed further experiments to characterize the nature of the inactive MHC fraction probed by the initial rate experiments. Although only $2-10 \%$ of the total MHC protein contributed to the initial rate processes, a much larger fraction, typically $50-90 \%$ for recombinant empty DR1 from various sources $(25,28)$, is able to bind peptide during a typical peptide loading protocol. For example, $>65 \%$ of an empty DR1 preparation from $S f 9$ insect cells was able to bind peptide after 3 days at $37^{\circ} \mathrm{C}$, as measured by a gel electrophoresis assay (Figure 6a). This suggests that the fraction of MHC protein that is inactive in the initial rate experiments can convert during a long 

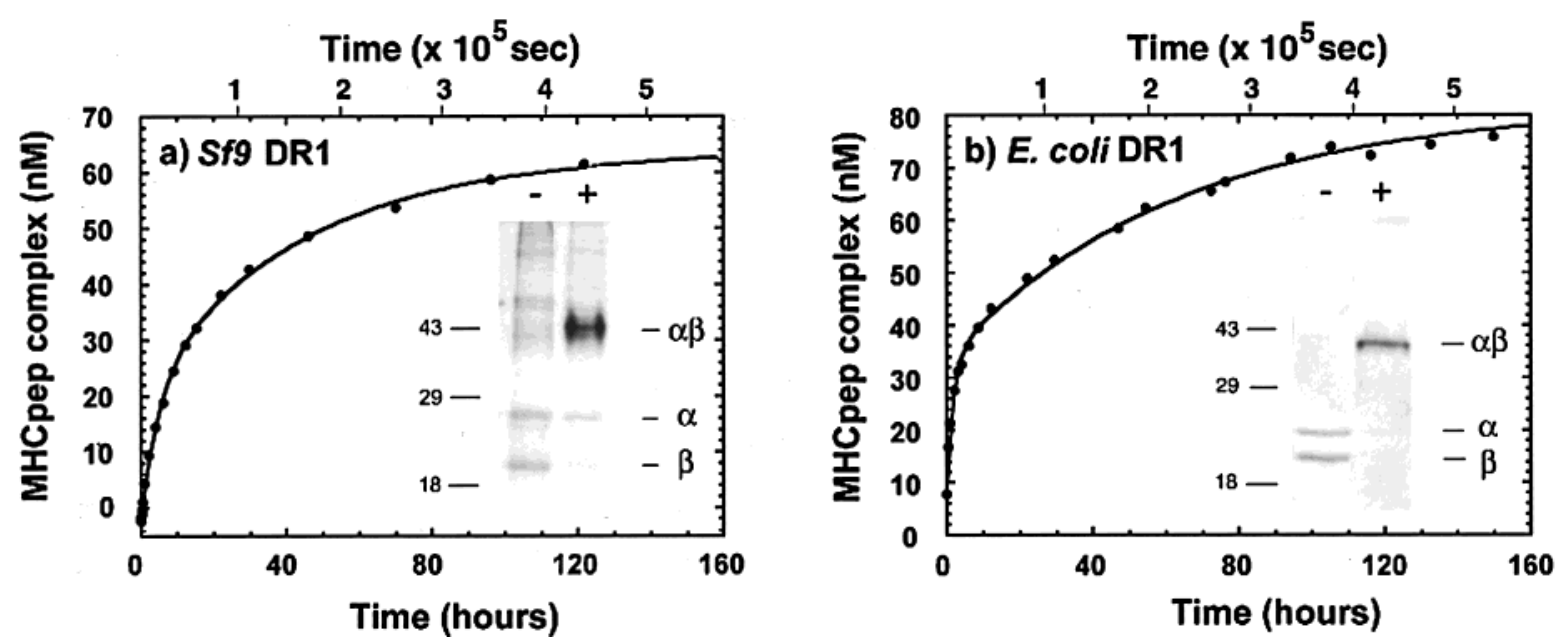

FIGURE 6: Overall reaction profile for (a) DR1/Sf9 and (b) DR1/E. coli. Association assay for DR1-HA complexes, with emission spectra recorded at indicated times after addition of AMCA-labeled peptide $(100 \mathrm{nM})$ to empty DR1 $(100 \mathrm{nM})$ at $37^{\circ} \mathrm{C}$, pH 7.2 . Emission intensity at $447 \mathrm{nM}$ increases with time, indicating binding of labeled peptide. Insets show 12.5\% SDS-PAGE for (a) DR1/Sf9 and (b) E. coli. DR1 was incubated with (+) and without $(-)$ HA peptide at $37^{\circ} \mathrm{C}$ for 3 days. After incubation, samples were mixed with Laemmli loading buffer and were not boiled prior to loading.

incubation into an active form competent to bind peptide. To investigate processes occurring over these longer time scales, we followed HA peptide binding by the FRET assay for several days (Figure 6a). Two kinetic processes were observed, one corresponding to the process described by the initial rate data, with $\tau=5 \mathrm{~h}$, and one much slower, with $\tau=43 \mathrm{~h}$. The final extent of peptide binding observed in this assay, $\sim 60 \%$, agrees with that determined in the gel assay. Extended preincubation under the reaction conditions but in the absence of peptide had no effect on the MHC conversion (not shown). Thus, as the active protein binds peptide during the course of the reaction, inactive protein is converted slowly into the active form to maintain the equilibrium.

Monomeric MHC Class II from E. coli. One possibility for the slow activation process might be disaggregation of aggregated MHC protein. Empty MHC class II proteins produced in insect cells have a distinct tendency to aggregate (25), and usually are isolated as a mixture of monomers, dimers, and higher order oligomers with a specific profile on size-exclusion chromatography (Figure 7, dashed line). Upon peptide binding, the oligomerization of the empty protein is reversed, and peptide complexes are monomeric (25). Thus, the slow kinetic process observed above could represent MHC disaggregation driven by removal of monomeric MHC from the equilibrium mixture of aggregation states. To investigate this possibility, we made use of empty MHC class II proteins prepared by folding together DR $\alpha$ and $\operatorname{DR} \beta$ subunits produced individually in $E$. coli inclusion bodies (28). The folding procedure can be carried out using low concentrations of protein in glycerol at $4{ }^{\circ} \mathrm{C}$, conditions which minimize aggregation of the empty protein, and can be used to prepare monomeric empty DR1 essentially free of aggregated material (Figure 7, solid line) and fully competent to bind peptide (Figure 6b). Monomeric empty DR1 prepared by refolding will oligomerize very slowly under the assay conditions, with a time constant of $\tau=\sim 10^{7}$ $\mathrm{s}$ or $\sim 9$ days (not shown). We used monomeric DR1 from E. coli to investigate the effect of aggregation on the kinetic steps described above. The dependence of the initial rates of reaction in both MHC and peptide titration experiments

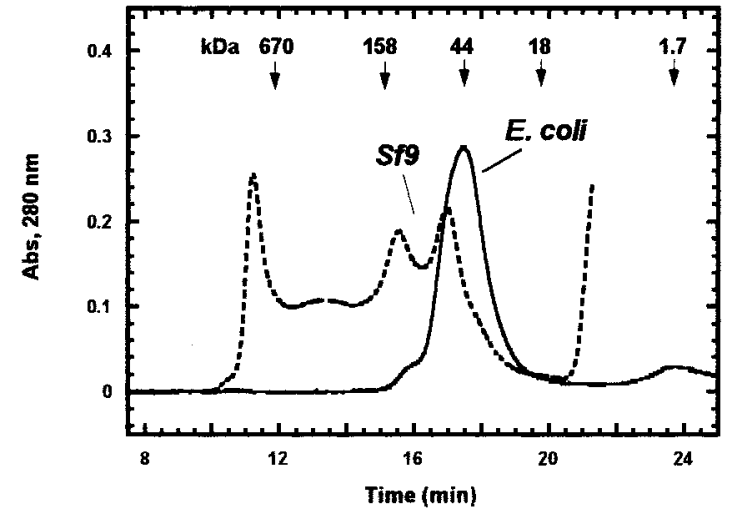

FIGURE 7: Monomeric DR1 produced in E. coli. Comparison of gel filtration profiles for DR1 produced in baculovirus-infected insect cells (dashed line) and monomeric DR1 refolded in vitro from subunits expressed in $E$. coli (solid line). The arrows above the plot indicate the positions of molecular weight standards. The species eluting at times $>20$ min represent buffer components in the insect cell preparation.

was similar to that observed for DR1 produced in insect cells, with bimolecular behavior at low concentration and saturating behavior at high concentrations (Figure 8). The high concentration regime of the monomeric DR1 titration plot (Figure $8 b$ ) could not be investigated due to MHC aggregation under these conditions; nonetheless, the concentration dependence of the initial rate is clearly hyperbolic and not linear. Kinetic parameters $k_{-1} / k_{1}$ and $k_{2}$ derived from the fit to eq 2 differed in the peptide and protein titration experiments, in the same manner as values for DR1 produced in insect cells (Table 2). As before, the differences could be explained by a low fraction of the total MHC able to participate in the initial rate processes, which was determined to be $2-3 \%$ of the total monomeric E. coli DR1 (Table 2). In overall progress curves measured over a long time base, the monomeric DR1 from E. coli exhibited two kinetic phases, a faster phase consistent with the initial rate data $(\tau$ $=2 \mathrm{~h})$ and a much slower phase $(\tau=64 \mathrm{~h})$ (Figure 6b). Overall, the nonaggregated monomeric protein from E. coli exhibited essentially identical kinetic behavior to protein from insect cells that contained mostly aggregated material. Thus, 

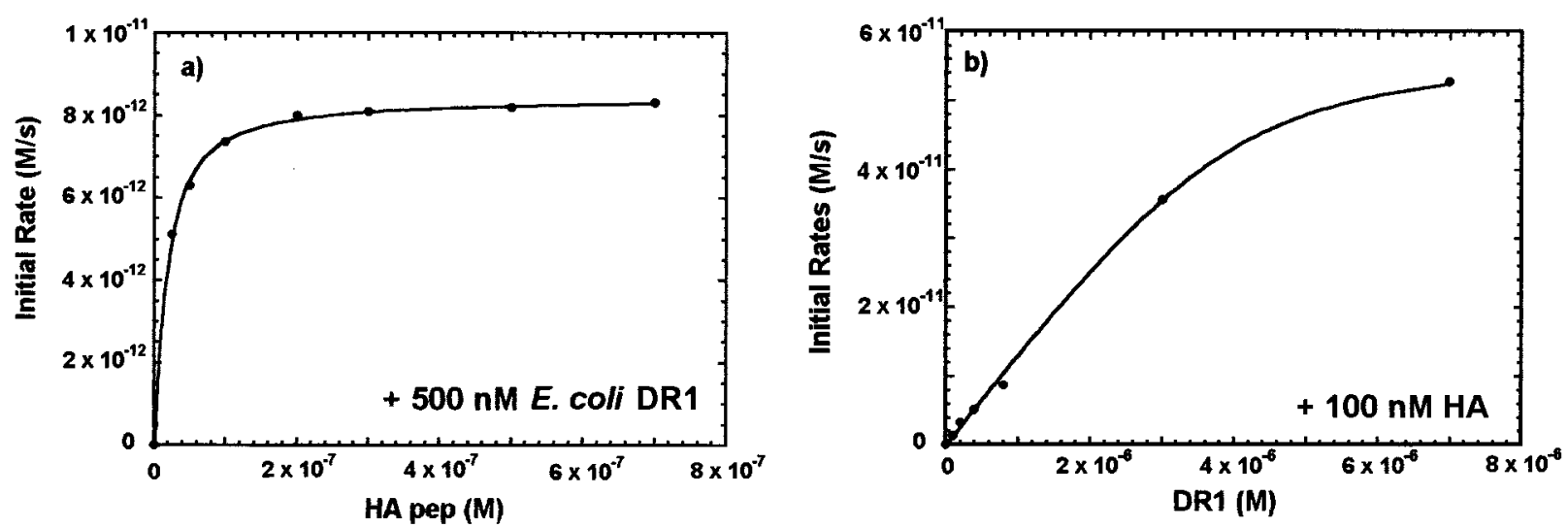

FIGURE 8: Initial rates of binding for monomeric DR1. (a) Dependence of peptide binding kinetics on peptide concentration for monomeric DR1 from E. coli, using $500 \mathrm{nM}$ DR1 and varying concentrations of AMCA-HA peptide. The initial rate of peptide binding is plotted against HA peptide concentration. The rates were determined from linear fits to the data (not shown). (b) Dependence of peptide binding kinetics on monomeric DR1 concentration, for $100 \mathrm{nM}$ AMCA-HA peptide and variable concentrations of monomeric DR1 corrected for the fraction of active protein. The initial rate of peptide binding is plotted against concentration of monomeric DR1. Compare panels A and $\mathrm{B}$ with Figures $3 \mathrm{~b}$ and $4 \mathrm{~b}$.

the inactive MHC fraction cannot be identified with aggregated protein, but rather with an inactive conformer present in both monomeric and oligomeric forms that can slowly convert to an active species during extended peptide binding reactions.

\section{DISCUSSION}

We have developed a fluorescence assay that we have used to monitor in real time the DR1-peptide binding reaction in situ. The initial rate of the peptide binding reaction is concentration-dependent at low reactant concentrations, suggesting a bimolecular reaction step. At high reactant concentration, the initial rate no longer shows a concentration dependence, suggesting that a rate-limiting unimolecular step follows the initial bimolecular reaction. This behavior explains the observed variation in forward rate constants for previous studies of MHC peptide binding: the apparent rate constant depends on the concentration regime used for the measurement. The kinetic parameters extracted from experiments that measured the dependence of the initial rate on DR1 concentration differed from those extracted from experiments which measured the dependence on peptide concentration. This behavior was observed for both HA and CLIP peptides. The differences were consistent with a small, active fraction of the total DR1 preparation participating in the initial phase of the reaction. When the concentration of DR1 was corrected to reflect the active percentage of protein participating in the reaction, the kinetic parameters extracted from either type of experiment were approximately equal. The progress of the reaction tracked over a time course of days indicated that most of the total DR1 eventually bound peptide. The progress curves for peptide binding were biphasic, with the first phase corresponding to the initial rate data, and the second phase corresponding to another step with a very long time scale. It appeared from these data that although a large fraction of DR1 is not active initially, it becomes so over time. Because a monomeric form of DR1 shows similar kinetic behavior to aggregated DR1, the mechanism of inactivation is unlikely to be aggregation, and instead appears to be a conformational change in the empty protein. Overall, these kinetic data can be described by the three-step mechanism shown in Figure 9. Peptide rapidly

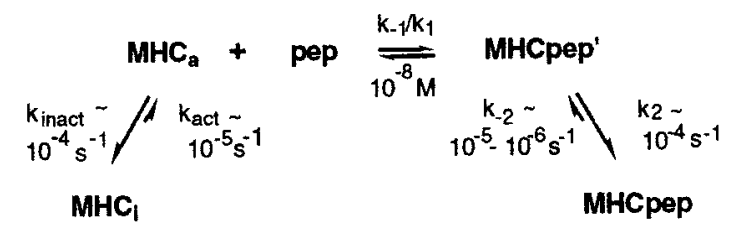

FIGURE 9: Kinetic mechanism for peptide binding to the class II MHC protein HLA-DR1. MHC $\mathrm{i}_{\mathrm{i}}$ and $\mathrm{MHC}_{\mathrm{a}}$ represent inactive and active conformations of the empty protein, and MHCpep' represents a transient peptide-bound species. Kinetic values are representative of both HA and CLIP peptide binding reactions.

binds to the active conformer $\mathrm{MHC}_{\mathrm{a}}$ to form the transient intermediate complex MHCpep'. We were not able to resolve the formation of this species with stopped-flow experiments ( $\sim 2 \mathrm{~ms}$ resolution). The intermediate complex slowly undergoes a conformational change to form the stable MHCpep species. As the active conformer $\mathrm{MHC}_{\mathrm{a}}$ becomes depleted, the inactive conformer $\mathrm{MHC}_{\mathrm{i}}$ slowly converts into the active form competent to bind peptide.

Various aspects of the proposed mechanism have been suggested by previous studies. It has been suggested that peptide binding to empty MHC proteins occurs with rapid formation of a loosely bound intermediate complex which then slowly converts to a compact, peptide-loaded, conformation $(31,33)$. Hydrodynamic studies showing that the radius of empty DR1 is $10-20 \%$ larger than for the stable, peptide-loaded complex support the existence of an "open" empty state which may be able to loosely bind peptides until conversion to the stable "compact" peptide-loaded conformation (42). For a murine class II MHC molecule, short- and long-lived MHCpep conformers were found in a $\mathrm{pH}$ dependent equilibrium (52). However, the peptide binding reactions of HLA-DR1, unlike those of some other class II MHC proteins, have been observed to have no major $\mathrm{pH}$ dependence $(38,53)$ (R.V.J. and L.J.S., unpublished observations). The postulated conversion between active and inactive MHC conformers (Figure 9) is supported by other recent studies $(37,38)$ showing that empty MHC proteins are in a "peptide-receptive" state when freshly dissociated from a complex with peptide, which we believe corresponds to the "active" MHC in our mechanism. The existence of different conformations for empty DR1 is also supported by the wider distribution of hydrodynamic radii observed for empty 
relative to peptide-loaded DR1 (42). The three-step mechanism proposed above affords a way to bridge all of these observations.

Our results suggest a possible mechanism of action for HLA-DM, the catalytic peptide exchange factor required for efficient peptide loading in vivo (4). The catalytic activity of HLA-DM was originally identified as increasing the rate of peptide exchange (54-56). Subsequently, HLA-DM was shown to promote peptide binding to empty HLA-DR1 (51) and to stabilize HLA-DR against inactivation in the absence of peptide (57). All of these activities could be explained by a model in which HLA-DM binds one of the intermediates transiently formed between $\mathrm{MHC}_{\mathrm{i}}$ and $\mathrm{MHCpep}$, thereby lowering the barrier for both the forward and reverse reactions, and shifting the equilibria away from $\mathrm{MHC}_{\mathrm{i}}$ (Figure 9). The observation that HLA-DM catalyzes peptide exchange to an extent directly proportional to the off-rate of the peptide from the $\mathrm{MHC}(58)$ is consistent with either or both $\mathrm{MHC}_{\mathrm{a}}$ and $\mathrm{MHCpep}^{\prime}$ as the intermediate species bound by HLA-DM. In an attractive correlation between the kinetic species observed here and conformational variants observed in previous hydrodynamic and spectroscopic studies (42), both $\mathrm{MHC}_{\mathrm{a}}$ and $\mathrm{MHCpep}$ ' would correspond to the "open" conformation, and convert to the "closed" forms $\mathrm{MHC}_{\mathrm{i}}$ and MHCpep in kinetic steps $k_{\mathrm{i}}$ and $k_{2}$.

Differences in the kinetic behavior of the DR1-HA and DR1-CLIP complexes can be traced to the kinetic stability of the final MHCpep complex. HA is a viral peptide that represents an immunodominant epitope in the response to influenza virus. CLIP is a fragment of the MHC-associated chaperonin invariant chain (Ii) that transiently occupies the MHC binding site during intracellular trafficking. HA and CLIP show similar behavior in the initial rate experiments; both bind rapidly to form transient intermediates with similar $k_{-1} / k_{1}$, which slowly convert to final MHCpep complexes with similar saturating rates $k_{2}$ (Figure 9). However, our measurements of the off-rates of each peptide indicate that CLIP's off-rate is 10-fold higher than that of HA (Table 2). The final MHCpep complex with HA is long-lived, and in the biological context is essentially irreversible. The equilibrium between intermediate MHCpep' and stable MHCpep conformations favors the formation of MHCpep for such irreversible complexes. On the other hand, the MHCpep complex with CLIP is unstable and dissociates relatively rapidly, with the equilibrium shifted to favor partial formation of the intermediate MHCpep'. The biological role of the CLIP peptide is to stabilize MHC class II molecules during transport and then to be exchanged for immunologically relevant endosomal peptides $(2,59)$. It is interesting that CLIP has apparently evolved to stabilize the MHCpep' intermediate species for facile HLA-DM-mediated exchange.

How do these kinetic processes fit into cellular antigen metabolism? The inactive species $\mathrm{MHC}_{\mathrm{i}}$ most likely does not normally occur in the cell, presumably due to the effect of HLA-DM (60) and invariant chain Ii. Newly synthesized class II MHC molecules immediately associate with invariant chain, which maintains the equilibrium toward complex formation and away from the inactive form. After trafficking of the MHC-Ii complex to the endosome under the influence of Ii targeting signals (61) and proteolysis of Ii in the endosome to leave CLIP in the binding site, the relevant reaction step would become peptide exchange under endo- somal peptide concentration (62). Thus, MHC molecules enter into the kinetic mechanism at the MHCpep stage, with peptide exchange through MHCpep' and $\mathrm{MHC}_{\mathrm{a}}$ facilitated by HLA-DM (Figure 9). The inactive form $\mathrm{MHC}_{\mathrm{i}}$ normally would not become populated in vivo under endosomal peptide concentrations. Recognition and disposal of any endosomal $\mathrm{MHC}_{\mathrm{i}}$ that had formed from molecules that did not acquire peptide despite prolonged residence in the endosome could act as a safety valve in B cells to prevent inappropriate surface expression of empty molecules. The physical basis for this recognition which regulates intracellular MHC trafficking may depend on the conformational transformations described by the three-step kinetic model.

\section{ACKNOWLEDGMENT}

We thank Mia Rushe for excellent technical assistance, George Gassner and the Lippard laboratory for assistance and use of a stopped-flow apparatus, Stuart Licht and Shannon Stahl for helpful discussions, and MIT Biopolymers Laboratory for peptide synthesis.

\section{REFERENCES}

1. Germain, R. N. (1994) Cell 76, 287-299.

2. Watts, C. (1997) Annu. Rev. Immunol. 15, 821-850.

3. Cresswell, P. (1996) Cell 84, 505-507.

4. Kropshofer, H., Hammerling, G. J., and Vogt, A. B. (1997) Immunol. Today 18, 77-82.

5. Brown, J. H., et al. (1993) Nature 364, 33-39.

6. Dessen, A., Lawrence, C. M., Cupo, S., Zaller, D. M., and Wiley, D. C. (1997) Immunity 7, 473.

7. Fremont, D. H., Hendrickson, W. A., Marrack, P., and Kappler, J. (1996) Science 272, 1001-1004.

8. Fremont, D. G., Monnaie, D., Nelson, C. A., Hendrickson, W. A., and Unanue, E. (1998) Immunity 8, 305-317.

9. Ghosh, P., Amaya, M., Mellins, E., and Wiley, D. C. (1995) Nature 378, 457-462.

10. Murthy, V., and Stern, L. J. (1997) Structure 5, 1385-1396.

11. Scott, C. A., Peterson, P. A., Teyton, L., and Wilson, I. A. (1998) Immunity 8, 319-329.

12. Smith, K. J., et al. (1998) J. Exp. Med. 188, 1511-1520.

13. Stern, L. J., Brown, J. H., Jardetzky, T. S., Gorga, J. C., Urban, R. G., Strominger, J. L., and Wiley, D. C. (1994) Nature 368, $215-221$.

14. Roche, P. A., and Cresswell, P. (1990) J. Immunol. 144, 18491856.

15. Rudensky, A. Y., Preston-Hurlburt, P., Al-Ramadi, B. J., Rothbard, J., and Janeway, C. A. (1992) Nature 359, 429431.

16. Hunt, D. F., Henderson, R. A., Shabanowitz, J., Sakaguchi, K., Michel, H., Sevilir, N., Cox, A. L., Appella, E., and Engelhard, V. H. (1992) Science 255, 1261-1263.

17. Chicz, R. M., Urban, R. G., Lane, W. S., Gorga, J. C., Stern, L. J., Vignali, D. A. A., and Strominger, J. L. (1992) Nature 358.

18. Buus, S., Sette, A., Colon, S. M., and Grey, H. M. (1988) Science 242, 1045-1047.

19. Gorga, J. C., Horejsi, V., Johnson, D. R., Raghupathy, R., and Strominger, J. L. (1987) J. Biol. Chem. 262, 16087-16094.

20. Reay, P., Wettstein, D. A., and Davis, M. M. (1992) EMBO J. 11, 2829.

21. Tampe, R., and McConnell, H. M. (1991) Proc. Natl. Acad. Sci. U.S.A. 88, 4661-4665.

22. Witt, S. N., and McConnell, H. M. (1993) Acc. Chem. Res. $26,442-448$.

23. Berezhkovskiy, L. M. (1998) Biophys. Chem. 71, 1-8.

24. Scott, C. A., Garcia, K. C., Carbone, F. R., Wilson, I. A., and Teyton, L. (1996) J. Exp. Med. 183, 2087-2095.

25. Stern, L. J., and Wiley, D. C. (1992) Cell 68, 465-477. 
26. Stockel, J., Meinl, E., Hahnel, C., Malotka, J., Seitz, R., Drexler, K., Wekerle, H., and Dornmair, K. (1994) J. Biol. Chem. 269, 29571-29578.

27. Wettstein, D. A., Boniface, J. J., Reay, P. A., Schild, H., and Davis, M. M. (1991) J. Exp. Med. 174, 219-228.

28. Frayser, M., Sato, A. K., Xu, L., and Stern, L. J. (1999) Protein Expression Purif. 15, 104.

29. Buus, S., Sette, A., Colon, S. M., Jenis, D. M., and Grey, H. M. (1986) Cell 47, 1071-1077.

30. Mason, K., and McConnell, H. M. (1994) Proc. Natl. Acad. Sci. U.S.A. 91, 12463-12466.

31. Sadegh-Nasseri, S., Stern, L. J., Wiley, D. C., and Germain, R. N. (1994) Nature 370, 647-650.

32. Witt, S. N., and McConnell, H. M. (1994) Biochemistry 33, 1861-1868.

33. Sadegh-Nasseri, S., and McConnell, H. M. (1989) Nature 337, 274-276.

34. Tompkins, S. M., Moore, J. C., and Jensen, P. E. (1996) J. Exp. Med. 183, 857-866.

35. Dornmair, K., Rothenhausler, B., and McConnell, H. M. (1989) Cold Spring Harbor Symp. Quant. Biol. 54, 409-416.

36. Beeson, C., and McConnell, H. M. (1994) Proc. Natl. Acad. Sci. U.S.A. 91, 8842-8845.

37. Natarajan, S. K., Assadi, M., and Sadegh-Nasseri, S. (1999) J. Immunol. 162, 4030-4036.

38. Rabinowitz, J. D., Vrljic, M., Kasson, P. M., Liang, M. N., Busch, R., Boniface, J. J., Davis, M. M., and McConnell, H. M. (1998) Immunity 9, 699-709.

39. Lamb, J., Eckels, D., Lake, P., Woody, J., and Green, M. (1982) Nature 300, 66-69.

40. Lamb, J., Eckels, D., Phelan, M., Lake, P., and Woody, J. (1982) J. Immunol. 128, 1428-1432.

41. Rothbard, J. B., Lechler, R. I., Howland, K., Bal, V., Eckels, D. D., Sekaly, R., Long, E., Taylor, W. R., and Lamb, J. (1988) Cell 52, 515-523.

42. Zarutskie, J. A., Sato, A. K., Rushe, M. M., Chan, I. C., Lomakin, A., Benedek, G. B., and Stern, L. J. (1999) Biochemistry 38, 5878-5887.

43. Jensen, P. E., Moore, J. C., and Lukacher, A. E. (1998) J. Immunol. Methods 215, 71.
44. Beeson, C., and McConnell, H. M. (1995) J. Am. Chem. Soc. 117, 10429-10433.

45. Wu, P., and Brand, L. (1994) Anal. Biochem. 218, 1-13.

46. Cantor, C. R., and Schimmel, P. R. (1980) Biophysical Chemistry, Vol. II, W. H. Freeman and Company, New York.

47. O'Sullivan, D., et al. (1991) J. Immunol. 147, 2663-2669.

48. Hammer, J., Belunis, C., Bolin, D., Papdopoulos, J., Walsky, R., Higelin, J., Danho, W., Sinigaglia, F., and Nagy, Z. A. (1994) Proc. Natl. Acad. Sci. U.S.A. 91, 4456-4460.

49. Jardetzky, T. S., Gorga, J. C., Busch, R., Rothbard, J., Strominger, J. L., and Wiley, D. C. (1990) EMBO J. 9, 17971803.

50. Hammer, J., Bono, E., Gallazzi, F., Belunis, C., Nagy, Z., and Sinigaglia, F. (1994) J. Exp. Med. 180, 2353-2358.

51. Kropshofer, H., Vogt, A. B., and Hammerling, G. J. (1995) Proc. Natl. Acad. Sci. U.S.A. 92, 8313-8317.

52. Schmitt, L., Boniface, J. J., Davis, M. M., and McConnell, H. M. (1998) Biochemistry 37, 1731-1738.

53. Sette, A., Southwood, S., O'Sullivan, D., Gaeta, F. C. A., Sidney, J., and Grey, H. M. (1992) J. Immunol. 3, 844-851.

54. Sloan, V. S., Cameron, P., Porter, G., Gammon, M., Amaya, M., Mellins, E., and Zaller, D. M. (1995) Nature 375, 802806.

55. Denzin, L. K., and Cresswell, P. (1995) Cell 82, 155-165.

56. Sherman, M. A., Weber, D. A., and Jensen, P. E. (1995) Cell 3, 197-205.

57. Kropshofer, H., Arndt, S. O., Moldenhauer, G., Hammerling, G. J., and Vogt, A. B. (1997) Immunity 6, 293-302.

58. Weber, D., Evavold, B. D., and Jensen, P. E. (1996) Science 274, 618-620.

59. Zhong, G., Castellino, F., Romagnoli, P., and Germain, R. N. (1996) J. Exp. Med. 184, 2061-2066.

60. Sherman, M. A., Weber, D. A., Spotts, E. A., Moore J. C., and Jensen, P. E. (1997) Cell. Immunol. 182, 1-11.

61. Pieters, J., Bakke, O., Dobberstein, B. (1993) J. Cell Sci. 106, $831-846$.

62. Germain, R. N., and Hendrix, L. R. (1991) Nature 353, 134-139.

BI9923656 